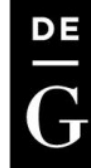

DOI 10.2478/pesd-2014-0031

PESD, VOL. 8, no. 2, 2014

\title{
GEOSTATISTICAL APPROACH TO FIND 'HOTSPOTS' WHERE BIODIVERSITY IS AT RISK IN A TRANSITION COUNTRY
}

\author{
Alexandru-Ionuţ Petrişor ${ }^{1}$, Liliana Petrişor ${ }^{1}$ \\ Key-words: land cover and use changes; CORINE; transitional dynamics; kriging; \\ desertification
}

\begin{abstract}
Global change' is a relatively recent concept, related to the energy - land use - climate change nexus, and designated to include all changes produced by the human species and the consequences of its activities over natural ecological complexes and biodiversity. The joint effects of these drivers of change are particularly relevant to understanding the changes of biodiversity. This study overlaps results of previous studies developed in Romania to find, explain and predict potential threats on biodiversity, including the effects of very high temperatures and low precipitations, urban sprawl and deforestation in order to identify 'hotspots' of high risk for the loss of biodiversity using geostatistical tools. The results found two hotspots, one in the center and the other one in the south, and show that the area affected by three factors simultaneously represents $0.2 \%$ of the national territory, while paired effects cover $4 \%$ of it. The methodological advantage of this approach is its capacity to pinpoint hotspots with practical relevance. Nevertheless, its generalizing character impairs its use at the local scale..
\end{abstract}

\section{Introduction}

The spatial sprawl of human society is due to the growth of population and increasing human needs. Possible outcomes include: (1) substitution, simplification and fragmentation of natural systems, resulting into restricting their connectivity; (2) increased heterogeneity and specialization of man-dominated systems, increasing mass and energy flows and dumping pollutants in the natural ones; (3) linearization of biogeochemical cycles, resulting into the concentration of mineral substances in waste, and exhaustion of natural resources; (4) increasing

\footnotetext{
1"Ion Mincu" University of Architecture and Urbanism \& National Institute for Research and Development in Constructions, Urbanism and Sustainable Spatial Development URBAN-INCERC, alexandru_petrisor@yahoo.com
} 
interdependence of subsystems expands their scale to the regional and global one (Vădineanu, 1998; Jongman, 2003). 'Global change' is a new concept used to refer all man-driven changes of the whole ecosphere: climate change, land use alterations, and change of energy flows (Dale et al., 2011), including their close inter-relationships (Dale, 1997; You, 2001; Dale et al., 2009; Petrişor et al., 2012c).

Previous studies showed the importance of energy, as human activities use energy from natural systems, creating additional trophy levels, such as technotrophy (use of energy in industry) or noo-trophy (use in support activities, such as research or management), connecting man-dominated systems to natural ones in order to find the energy and resources needed for their functioning (Ianoş, 2000b; Petrişor and Sârbu, 2010). The concept of 'primary eco-energy' ties energy to land use and means the initial energy of a system before conscious man intervention over its structure (Ianoş, 2000b). A study carried out in Sărăţel river basin underlined tight links between land cover and use changes and consumption of primary eco-energy (Ianoş et al., 2011). Jensen (2000) shows that 'land cover' means what can be found on the ground from a biophysical perspective, and 'land use' shows its usage by humans. However, the second is valid for man-dominated systems; in natural systems, 'land use' shows their more detailed classification (Petrişor et al., 2010).

Changes of land cover and use can be investigated using satellite data (Zhao et al., 2003). The European Union uses CORINE classification of land cover and use, with three levels; the first one reflects land cover and the second land use, in more or less detail (de Lima, 2005). Since CORINE data cover the whole European continent, only three data sets are available from 1990, 2000, and 2006. Due to their spatial and temporal extent, CORINE data are useful to analyze long term changes of large territories (Petrişor et al., 2010; Petrişor, 2012b).

The effects of climate change, land use and energy on biodiversity were investigated by numerous studies. Climate change decreases overall diversity through effects on individuals, species and ecosystems (Dukes and Mooney, 1999; Thomas et al., 2004; Parmesan, 2006), but can favor invasive species (Penuelas and Filella, 2001; Penuelas et al., 2002; Patz et al., 2008). The effects of altered land use differ with respect to their nature; deforestation and urbanization result into the loss of biodiversity (Jongman, 2003; Petrişor et al., 2010; Chelaru and Apostol, 2012), although urbanization can favor invasive species (Wang et al., 2011). The two can alter the energy balance, and have synergetic effects (Dale, 1997; Dale et al. 20011; Petrişor et al., 2012c). Conservationists aim to identify 'biodiversity hotspots' where the action of more stressors overlaps, and are a priority for conservation (Gillespie et al., 2012). Therefore, it is important to analyze connections spatially (Matin et al., 2012). 
The connections between man-driven environmental changes and underlying causes, between the different pressures can be underlined if the analysis of spatial data (e.g., land cover and use data) is carried out in conjunction with statistical approaches (Benning et al., 2002). Previous studies carried out at in Romania looked at the influence of climate change and land use alterations on natural ecosystems. Climate change studies have analyzed the influence of increasing temperatures (Petrişor, 2010) and decreasing precipitations (Petrişor, 2011) on biodiversity and natural protected areas in Romania and their relationship with land cover and use changes occurring between 1990-2006 (Petrişor, 2012c). Studies looking at land cover and use changes were carried out over the entire territory for all types of changes (Petrişor, 2012a), with a special focus on urbanization (Petrişor et al., 2010; Petrişor, 2012b), or over particular areas, in relationship with the distribution of primary eco-energy (Ianoş et al., 2011). The last two studies identified 'hotspots' of intense transitional dynamics such as urbanization, deforestation, afforestation or reforestation, agricultural abandon or development, and discussed them in relationship with the socio-economic changes that occurred in Romania or particular areas investigated during the period covered by data, since these forces were the most important drivers of change (Petrişor et al., 2010).

This study aims to overlap, using geostatistical approaches, spatial data on the pressure of high temperatures, low precipitations, urbanization and deforestation to identify the 'hotspots' most likely to indicate the loss of biodiversity, considered areas at highest risk, starting from the hypothesis according to which the most important driver of change in a transition country is the unwise management of land, resulting into environmental impacts aggravated by the consequences of climate change.

\section{Data and methods}

CORINE land cover and use changes data are freely offered by the European Environment Agency (EEA). The two data sets reflect changes occurred between 1990 and 2000 (http://www.eea.europa.eu/data-and-maps/data/corine-land-cover1990) and 2000-2006 (http://www.eea.europa.eu/data-and-maps/data/corine-landcover-2000). Climate change data are freely available from Berkeley University in DIVA-GIS format (Hijmans et al., 2001) at http://biogeo.berkeley.edu/worldclim/diva/diva_worldclim_2-5m.zip (current), and $\mathrm{http} / / /$ biogeo.berkeley.edu/worldclim/diva/diva_wc_ccm3_2-5m.zip (2100 predictions). Current data are a result of WorldClim project (Hijmans et al., 2003); 2100 predictions are based on double $\mathrm{CO}_{2}$ concentrations and the $\mathrm{CCM} 3$ model (Govindasamy et al., 2005).

CORINE data are in a GIS format. Climate data are in a specific format, converted to GIS files. Converted DIVA-GIS data is vector obtained by summing 
up $2.5 \mathrm{~min} \times 2.5 \mathrm{~min}$ raster cells. Spatial interpolation used the X-Tools extension of ArcView GIS 3.X was used to find the geometric center of each polygon, keeping the polygon attributes: area of parcels with changed land cover and use and difference between predicted and current temperatures or precipitations.

Two subsets were derived: a subset showing potential effects of climate change, including largest increase of temperatures and decrease of precipitations, and a subset with land cover and use changes attributable to urbanization and deforestations. The latest were chosen due to their importance underlined by previous studies (Ianoş et al., 2011; Petrişor, 2012a; Vartolomei, 2012). The largest increase of temperatures and decrease of precipitations were found looking at the histograms showing the statistical distribution of differences, and choosing intervals comparable in size for temperatures and precipitations and not exceeding $10 \%$ (Petrişor, 2011). Land cover changes attributable to urbanization included changes of other CORINE level 1 classes into 'artificial' and land use changes within the 'artificial' class indicating urban development (Petrișor et al., 2010; Petrişor, 2012b). Deforestation was defined by land cover changes of previous forest areas into other classes, not due to urbanization, and land use classes indicating deforestation (Petrişor, 2012c).

In order to analyze the joint action of stressors, the overlapping areas were computed. First, there is no area where all factors (high temperatures, low precipitations, urbanization and deforestation) occur together. However, particular joint action of two or three factors might be of interest; if high temperatures and low precipitations occur simultaneously, the area is at risk for desertification (You, 2001). The same is valid if deforestation acts together with high temperatures and/or low precipitations. The joint action of urbanization and high temperatures and/or low precipitations results into possible heat islands (Rizwan et al., 2008; Cheval and Dumitrescu, 2009; Cheval et al., 2009). However, instead of discussing all possible combinations, the study looked at the risk classified as 'high' if three factors act together, 'moderate' if only two factors join their effects, and low if a single factor acts.

\section{Results and discussion}

The map displayed in Fig. 1 shows the joint action of factors with potential impact on biodiversity. The risk for loss of biodiversity is considered 'high' if three stressors act jointly, 'moderate' if only two act together and 'low' if there is only one factor.

The figure shows that most factors resulting into the loss of biodiversity cover the mountain region; these areas are highly sensitive to climate changes (Keiler et al., 2010), particularly when subjected to deforestation (Knorn et al., 2012). European alpine regions are very important threatened systems with high 
biodiversity (Borsdorf and Braun, 2008) and high levels of primary eco-energy (Ianoş, 2000b).

These results are confirmed by the findings of previous studies, showing a central hotspot with the highest risk for the loss of biodiversity, due to the joint action of three stressors in small areas and of two stressors in an extended region surrounding it. This area appears to be affected by all types of stressors: urbanization, deforestations, high temperatures and low precipitations. In addition, the curvature of the Carpathians is the epicenter of most Romanian earthquakes (Boştenaru Dan, 2005; Georgescu and Pomonis, 2011). According to previous findings, primary eco-energies are present at high levels in the area (Ianoş, 2000b; Ianoş et al., 2011), indicating that anthropic pressures did not exist in the past. The neighboring region, situated in its western part is characterized by increased socioeconomic underdevelopment during the economic crisis (Muntean et al., 2010). This is probably the most relevant 'hotspot' where biodiversity is at risk. Previous studies show that some effects have already been documented; temperature and precipitation changes favored its colonization by alien species (Duduman et al., 2011; Sirbu and Oprea, 2011).

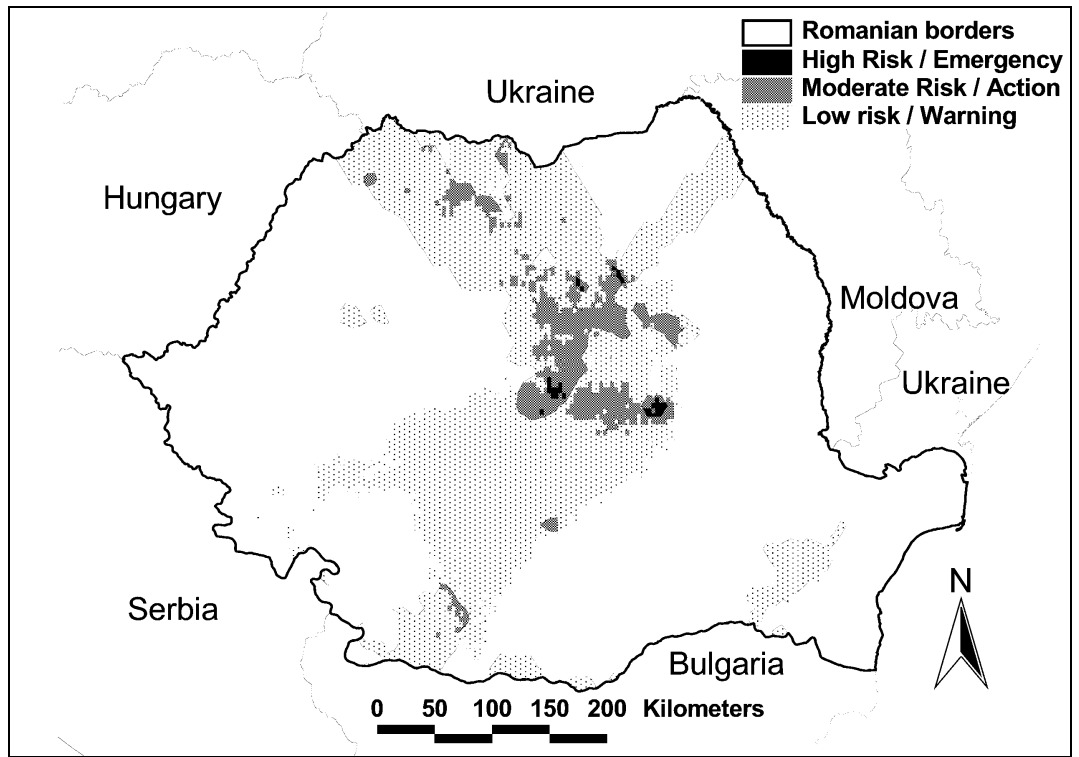

Fig. 1. Showing the joint action of factors resulting into the loss of biodiversity in Romania. The shading indicates the risk, considered 'high' (calling for urgent action) if three factors combine their action, 'moderate' (involving medium-term actions) if only two factors act jointly and 'low' (reclaiming long-term strategies) if only one factor is present. The map disregards the nature of stressors. 
In addition to the mountain regions, deforestations are likely to affect ecosystems situated in the Danube floodplain (southern and eastern Romania, close to the Bulgarian border), also prone to climate changes (Ionac and Grigore, 2012; Prăvălie, 2013). The massif deforestations in southern Romania, in conjunction with predicted growth of temperatures, are likely to be the cause of the desertification of this area at moderate risk. Other research confirmed changes of the composition of plant and animal communities, suggesting a desertification process (Marinică and Chimişliu, 2008; Vlăduţ, 2010; Meiţă et al., 2011; Petrişor et al., 2011; Corneanu et al., 2012; Rosu and Oiş̧te, 2013). Additional pressures are present in the area; the impacts of mining are still present (Braghină et al., 2010, 2011; Vartolomei et al., 2013), even though urban restructuring after 1989 resulted into the loss of the function of former industrial cities due to the decline of mining activities (Ianoş, 2000a).

Other areas at risk expand to the north, covering the mountain region. In a practical perspective, the 'low' risk constitutes a warning, calling for long-term strategies aimed to diminish individual pressures and mitigate their effects; 'moderate risk' calls for medium-term strategies resulting into concrete actions, while dealing with the 'high risk' is possible only through urgent actions.

The computations analyzing the joint action are showed in tables 1 and 2 . Table 1 shows the raw values of the area affected by each stressor - high temperature, low precipitations, urbanization and deforestation, of their paired action and of the joint action of three factors. As it has been shown in the previous section, there is no area where all four factors act together. In terms of magnitude, urbanization and low precipitations appear to be the most significant stressors. High temperatures affect approximately half of the area affected by each of them, and deforestations $1 / 3$ of it. The importance of urbanization has been stressed out by other studies (Neamţu, 2005; Grigorescu et al., 2012; Petrişor, 2012c; Suditu, 2012). The most important combinations of three factors are the ones between climate changes (high temperatures and low precipitations) and urbanization or deforestation. The joint effect of high temperatures, urbanization and deforestation affects approximately half of the area affected by any of them.

Table 2 sums up the information in table 1 disregarding the nature of stressors and accounting only for the number of factors acting together. It can be seen that as the number of factors acting together increases, the overlapping percentage decreases. Approximately one third of the country is affected by a single factor; the joint effects of two factors cover approximately $4 \%$ of the entire territory, and the area affected by three factors acting together makes up only $0.2 \%$ of the entire territory. These findings have a practical significance in terms of developing strategies or taking immediate action; it makes sense to act immediately for a very small portion of the territory and develop medium-term strategies for $4 \%$ of it. 
Tab. 1. Individual and joint effects of high temperatures, low precipitations, urbanization and deforestation against biodiversity in Romania based on geostatistical estimations. Values indicate affected area, in squared $\mathrm{km}$.; the total area of the country is $237,500 \mathrm{~km}^{2}$. Highlights indicate that a value is not computed if it replicates another one (gray) or the action of a third factor from the right column (light trellis)

\begin{tabular}{|c|c|c|c|c|c|c|c|c|}
\hline \multirow{3}{*}{$\begin{array}{c}\text { Second factor } \rightarrow \\
\text { First factor } \downarrow \\
\text { High } \\
\text { temperatures } \\
\end{array}$} & \multirow{3}{*}{$\begin{array}{c}\begin{array}{c}\text { High } \\
\text { temperatures }\end{array} \\
16158\end{array}$} & \multicolumn{2}{|c|}{\begin{tabular}{|c|} 
Low \\
precipitations
\end{tabular}} & \multicolumn{2}{|c|}{ Urbanization } & \multicolumn{2}{|c|}{ Deforestations } & \multirow{2}{*}{ 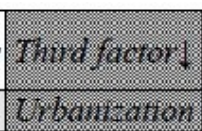 } \\
\hline & & \multirow{2}{*}{2322} & 164 & \multirow{2}{*}{5885} & \multirow[b]{2}{*}{ I } & \multirow{2}{*}{1074} & - & \\
\hline & & & 175 & & & & - & Defrarestation \\
\hline $\begin{array}{c}\text { Low } \\
\text { precipitations }\end{array}$ & - & \multicolumn{2}{|c|}{30575} & 1042 & 0.8 & 599 & - & Deforestation \\
\hline Urbanization & - & \multicolumn{2}{|c|}{-} & \multicolumn{2}{|c|}{31655} & \multicolumn{2}{|l|}{275} & - \\
\hline Deforestation & - & \multicolumn{2}{|c|}{-} & \multicolumn{2}{|c|}{-} & \multicolumn{2}{|l|}{9723} & - \\
\hline
\end{tabular}

Tab. 2. Individual and joint effects of high temperatures, low precipitations, urbanization and deforestation over biodiversity in Romania based on geostatistical estimations. Values indicate affected area, in squared $\mathrm{km}$.; the total area of the country is $237,500 \mathrm{~km}^{2}$

\begin{tabular}{lccc}
\hline \multicolumn{1}{c}{ Number of factors acting simultaneously $\rightarrow$} & 1 & 2 & 3 \\
$\begin{array}{l}\text { Parameter } \downarrow \\
\text { Area summed from all combinations //\% of national } \\
\text { territory }\end{array}$ & $88111 / / 37$ & $11198 / / 5$ & $430 / / 0$ \\
$\begin{array}{l}\text { Area excluding overlap //\% of national territory } \\
\% \text { overlap }\end{array}$ & $67005 / / 28$ & $9908 / / 4$ & $430 / / 0$ \\
\end{tabular}

In summary, the most important drivers of changes found responsible for potential effects against Romanian biodiversity were urban sprawl (consistent with the findings of Neamţu, 2005; Grigorescu et al., 2012; Suditu, 2012) and deforestation (also underlined by Roman, 2009; Dutcă and Abrudan, 2010). These factors are characteristic to transition countries (Ehrhardt-Martinez, 1998; Jorgenson and Burns, 2007; DeFries et al., 2010; Peptenatu et al., 2010), especially when in addition environmental awareness and consciousness are at low levels (Zhao et al., 2003; Ianoş et al., 2009).

Methodologically, while able to pinpoint hotspots, geostatistical tools have a great generalizing power, which is at the same time their most important limit. The first caveat is that results are theoretical constructs, based on probability estimations, and their limits are not necessarily real and precise (Petrişor et al., 2010; Petrişor, 2011). The second issue is causality; while some phenomena can explain the position of hotspots, the reverse is not necessarily true. Spurious hotspots might appear through statistical generalization without proving the existence of a certain process within their limits. 


\section{Conclusions}

This study spatially overlapped the effects of factors leading to the loss of biodiversity in Romania in order to find areas at highest risk. Climate change (increasing temperatures and decreasing precipitations) and land cover and use changes (urbanization and deforestation) were the most significant ones. Spatial analyses found an area close to the center of the country where all factors acted together, and another in the south, exposed mostly to climate changes. Vulnerable alpine regions were found at risk for the loss of biodiversity. The main causes, urbanization and deforestations, make Romania a typical case study for transition countries. Methodologically geostatistical tools were very useful to map the potential risks. Last but not least, the operational and practical utility of eco-energy in underlining human impacts was reconfirmed.

\section{References}

Benning Tracy L., Lapointe D, Atkinson C. T., Viotousek P. M. (2002), Interactions of climate change with biological invasions and land use in the Hawaiian Islands: Modeling the fate of endemic birds using a geographic information system, Proceedings of the National Academy of Sciences of the United States of America 99(22):14246-14249.

Borsdorf A., Braun Valerie (2008), The European and Global Dimension on Mountain Research, Journal of Alpine Research 96(4):117-129.

Boştenaru Dan Maria (2005), Multidisciplinary co-operation in building design according to urbanistic zoning and seismic microzonation, Natural Hazards and Earth System Sciences 5(3): 397-411.

Braghină C., Peptenatu D., Constantinescu S., Pintilii R. D., Drăghici C. (2010), The pressure exerted on the natural environment in the open pit exploitation areas in Oltenia, Carpathian Journal of Earth and Environmental Science 5(1):33-40.

Braghină C., Peptenatu D., Drăghici C., Pintilii R. D., Schvab A. (2011), Territorial management within the systems affected by mining Case study the South-Western Development Region in Romania, Iranian Journal of Environmental Health Science and Engineering 8(4):342-352.

Chelaru D.-A., Apostol L. (2012), Using GIS to analyse land use change in Bistriţa subcarpathian valley, Present Environment and Sustainable Development 6(2):315325.

Cheval S., Dumitrescu A. (2009), The July urban heat island of Bucharest as derived from MODIS images, Theoretical and Applied Climatology 96(1-2):145-153.

Cheval S., Dumitrescu A., Bell A. (2009), The urban heat island of Bucharest during the extreme high temperatures of July 2007, Theoretical and Applied Climatology 97(34):391-401. 
Corneanu Mihaela, Corneanu G., Cojocaru Luminița, Lăcătuşu Anca-Rovena (2012), Investigations to detect ecosystem disturbances under the influence of anthropogenic factors, Oltenia Journal of Studies in Natural Sciences 28(2):219-228.

Dale Virginia H. (1997), The relationship between land-use change and climate change, Ecological Applications 7(3):753-769.

Dale Virginia H., Efroymnson Rebecca A., Kline K. L. (2011), The land use-climate change-energy nexus, Landscape Ecology 26(6):755-773.

Dale Virginia H., Lannom K. O, Tharp M. L., Hodges D. G., Fogel J. (2009), Effects of climate change, land-use change, and invasive species on the ecology and tourism of the Cumberland Forests, Canadian Journal of Forest Research 39(2):467-480.

de Lima M. V. N. (2005), IMAGE2000 and CLC2000 Products and Methods, Institute for Environment and Sustainability, Ispra, Italy.

DeFries Ruth S., Rudel T., Uriarte Maria, Hansen M. (2010), Deforestation driven by urban population growth and agricultural trade in the twenty-first century, Natural Geosciences 3(3):178-181.

Duduman M.-L., Isaia Gabriela, Olenici N. (2011), Ips duplicatus. (Sahlberg) (Coleoptera: Curculionidae, Scolytinae) - Preliminary results, Bulletin of the Transilvania University of Brasov, Series II - Forestry, Wood Industry, and Agricultural Food Engineering 53(2):19-26.

Dukes J. S., Mooney H. A. (1999), Does global change increase the success of biological invaders? Trends in Ecology and Evolution 14(4):135-139.

Dutcă I., Abrudan I. V. (2010), Estimation of Forest Land Cover Change in Romania between 1990 and 2006., Bulletin of the Transilvania University of Brasov, Series II Forestry, Wood Industry, and Agricultural Food Engineering 52(1):33-36.

Ehrhardt-Martinez Karen (1998), Social Determinants of Deforestation in Developing Countries, Social Forces 77(2):567-586.

Georgescu E.-S., Pomonis A. (2011), A Review of Socio-Economic Consequences, Losses and Human Casualties of the 1977 Vrancea, Romania Earthquake, Constructions 12(2):21-43

Gillespie T. W., Lipkin, B. Sullivan Lauren, Benowitz D. R., Pau Stephanie, Keppel K. (2012), The rarest and least protected forests in biodiversity hotspots, Biodiversity and Conservation 21(14):3597-3611.

Govindasamy B., Duffy P. B., Coquard J. (2003), High resolution simulations of global, Part 2: Effects of increased greenhouse gases, Climate Dynamics 21(5/6):391-404.

Grigorescu Ines, Mitrică Bianca, Kucsicsa G., Popovici Elena Ana, Dumitraşcu Monica, Cuculici Roxana (2012), Post-communist land use changes related to urban sprawl in the Romanian metropolitan areas, Human Geographies 6(1): 73-77.

Hijmans R. J., Cameron Susan E., Parra J. L., Jones P. G., Jarvis A. (2005), Very high resolution interpolated climate surfaces for global land areas, International Journal of Climatology 25(5):1965-1978.

Hijmans R. J., Guarino L., Cruz M., Rojas E. (2001), Computer tools for spatial analysis of plant genetic resources data, Plant Genetic Resources Newsletter 127(1):15-19. 
Ianoş I. (2000), Romanian Towns: from Extensive Industrialisation to Ruralisation? Geographical Journal of Korea 34(2):125-136.

Ianoş I. (2000b), Territorial systems. A geographical approach [in Romanian], Technical Press, Bucharest, Romania.

Ianoş I., Peptenatu D., Zamfir Daniela (2009), Respect for environment and sustainable development, Carpathian Journal of Earth and Environmental Science 4(1):81-93.

Ianoş I., Petrişor A.-I., Stoica Ilinca Valentina, Sârbu C. N., Zamfir Daniela, Cercleux Andreea Loreta (2011), The different consuming of primary eco-energies and their degradation in territorial systems, Carpathian Journal of Earth and Environmental Sciences 6(2):251-260.

Ionac Nicoleta, Grigore Elena (2012), The bioclimatic stress due to overheating in the southern Dobrudjan tableland area, Present Environment and Sustainable Development 6(1):103-112.

Jensen J. R. (2000), Remote Sensing of the Environment. An Earth Resource Perspective, Prentice Hall, Upper Saddle River, NJ.

Jongman R. H. G. (2003), Ecological networks and greenways in Europe: reasoning and concepts, Journal of Environmental Sciences 15(2):173-181.

Jorgenson A. K., Burns T. J. (2007), Effects of rural and urban population dynamics and national development on deforestation rates 1990-2000, Sociological Inquiries 77(3):460-482.

Keiler Margreth, Knight J., Harrison S. (2010), Climate change and geomorphological hazards in the eastern European Alps, Philosophical Transactions of the Royal Society A: Mathematical, Physical, Engineering Sciences 368(1919):2461-2479.

Knorn J., Kuemmerle T., Radeloff V. C., Szabo Alina, Mîndrescu M., Keeton W. S., Abrudan I., Griffiths P., Gancz V., Hostert P. (2012), Forest restitution and the protected area effectiveness in post-socialist Romania, Biological Conservation 146(1):204-212.

Marinică I., Chimişliu Cornelia (2008), Climatic changes on regional plan in Oltenia and their effects on the biosphere. Oltenia Journal of Studies in Natural Sciences 24(1):221-229.

Matin S., Chitale V. S., Behera M. D., Mishra B., Roy P. S. (2012), Fauna data integration and species distribution modelling as two major advantages of geoinformatics-based phytobiodiversity study in today's fast changing climate, Biological Conservation 21(5):1229-1250.

Meiţă V., Petrişor A.-I., Simion-Melinte C.-P. (2011), Assessing the vulnerability to climate change in the Romanian part of Tisza river basin, Research Journal of Agricultural Sciences 43(3):429-436.

Muntean Mihaela-Carmen, Nistor Rozalia, Nistor C. (2010), Competitiveness of Developing Regions in Romania, WSEAS Transactions on Business and Economics 3(7):252-261.

Neamț Bogdana (2005), Urban sprawl from a comparative perspective: the case of US cities versus their Romanian counterparts. Is there any reason why we should worry? Transylvania Review of Administrative Sciences 15E(1):77-85. 
Parmesan Carmen (2006), Ecological and Evolutionary Responses to Recent Climate Change, Annual Review of Ecology and Systematics 37(1):637-669.

Patz J. A., Olson Sarah H., Uejio C. K., Gibbs Holly K. (2008), Disease Emergence from Global Climate and Land Use Change, Medical Clinics of North America 92(6):1473-1491.

Penuelas J., Filella Iolanda (2001), Responses to a Warming World, Science 294(5543):793-794.

Penuelas J., Filella Iolanda, Comas P. (2002), Changed plant and animal life cycles from 1952 to 2000 in the Mediterranean region, Global Change Biology 8(6):531-544.

Peptenatu D., Pintilii R. D., Drăghici C., Stoian Daniela (2010), Environmental pollution in functionally restructured urban areas: case study - the city of Bucharest, Iranian Journal of Environmental Health Sciences, Engineering 7(1):87-96.

Petrişor A.-I. (2010), GIS-based assessment of the landform distribution of 2100 predicted climate change and its influence on biodiversity and natural protected areas in Romania, Oltenia Journal of Studies in Natural Sciences 26(1):247-256.

Petrişor A.-I. (2011), GIS-based assessment of the distribution of 2100 predicted changes of precipitations and influence on biodiversity and natural protected areas in Romania, Studia Universitatis Vasile Goldis, Life Sciences Series 21(2):389-398.

Petrişor A.-I. (2012a), Dynamics of the environmental transformation processes during 1990-2006 in Romania reflected by land cover and use changes, Present Environment and Sustainable Development 6(1):353-365.

Petrişor A.-I. (2012b), Land cover and land use analysis of urban growth in Romania, Human Geographies 6(1):47-51.

Petrişor A.-I. (2012c), Land cover and use changes and predicted climate changes in Romania: connections underlined by their spatial distributions, Oltenia Journal of Studies in Natural Sciences 28(1):141-148.

Petrişor A.-I., Ianoş I., Tălângă C. (2010), Land cover and use changes focused on the urbanization processes in Romania, Environmental Engineering and Management Journal 9(6):765-771.

Petrişor A.-I., Meiţă V., Chicoş Alina, Peleanu I., Simion-Melinte C.-P. (2011), Assessing the Vulnerability to Climate Change in the Romanian Part of the Tisza River Basin, Romanian Review of Regional Studies 7(2):121-128

Petrişor A.-I., Sârbu C. N. (2010), Dynamics of geodiversity and eco-diversity in territorial systems. Journal of Urban and Regional Analysis 2(1):61-70.

Prăvălie R. (2013), Aspects regarding spatial and temporal dynamic of irrigated agricultural areas from southern Oltenia in the last two decades, Present Environment and Sustainable Development 7(2):133-143.

Rizwan A. M., Dennis Y. C. L., Liu C. (2008), A review on the generation, determination and mitigation of Urban Heat Island, Journal of Environmental Sciences 20(1):120128.

Roman T. (2009), The Forest of Romania: a Social-Economic Dramma, Theoretical and Applied Economics 535(1):57-64. 
Rosu L. I., Oiște Ana-Maria (2013), Defining critical areas through dispersion and density o vegetation index in relation to population. Study case: Iaşi City, Present Environment and Sustainable Development 7(2):193-204.

Sirbu C., Oprea A. (2011), New records in the alien flora of Romania (Artemisia argyi, A lavandulaefolia, and Europe, A lancea), Turkish Journal of Botany 35(6):717-728.

Suditu B. (2012), Urban sprawl - the legal context and territorial practices in Romania, Human Geographies 6(1):73-77.

Thomas C. D., Cameron Alison, Green R. E., Bakkenes M., Beaumont Linda J., Collingham Yvonne C., Erasmus B. F., De Siqueira M. F., Grainger A., Hannah L., Hughes L., Huntley B., Van Jaarsveld A .S., Midgley G. F., Miles Lera, Ortega-Huerta M. A., Peterson A. T., Phillips O. L., Williams S. E. (2004), Extinction risk from climate change, Nature 427(6970):145-148.

Vădineanu A. (1998), Sustainable development. Vol 1, Theoretical foundations [in Romanian], University of Bucharest Press, Bucharest, Romania.

Vartolomei F. (2012), Factors that increase dryness phenomenon on small rivers in Prut basin (analysis of conditionalities), Present Environment and Sustainable Development 6(1):341-351.

Vartolomei F., Damian R., Armass Iuliana (2013), Assessing the quality on natural environment in the context of the drilling exploitation and mining-site abandonment phenomena. The Ialomita subcarpathian area/Romania, Present Environment and Sustainable Development 7(1):244-255.

Vlăduț A. (2010), Ecoclimatic Indexes within the Oltenia Plain, Geographical Forum 9(9):49-56.

Wang H.-F., Lopez-Pujol J., Meyerson Laura A., Qiu J.-X., Wang X.-K., Ouyang Z.Y. (2011), Biological invasions in rapidly urbanizing areas: a case study of Beijing, China, Biological Conservation 20(11):2483-2509.

You S.-C. (2001), Agricultural adaptation to climate change in China, Journal of Environmental Sciences 13(2):192-197.

Zhao B., Nakagoshi N., Chen J.-K., Kong L.-Y. (2003), The impact of urban planning on land use and land cover in Pudong of Shanghai, China, Journal of Environmental Sciences 15(2):205-214. 